\title{
Increased blood-brain barrier permeability and altered tight junctions in experimental diabetes in the rat: contribution of hyperglycaemia and matrix metalloproteinases
}

\author{
B. T. Hawkins • T. F. Lundeen • K. M. Norwood • \\ H. L. Brooks • R. D. Egleton
}

Received: 12 July 2006 / Accepted: 14 September 2006 / Published online: 2 December 2006

(C) Springer-Verlag 2006

\begin{abstract}
Aims/hypothesis Although diabetes mellitus is associated with peripheral microvascular complications and increased risk of neurological events, the mechanisms by which diabetes disrupts the blood-brain barrier (BBB) are not known. Matrix metalloproteinase (MMP) activity is increased in diabetic patients, is associated with degradation of tight junction proteins, and is a known mediator of BBB compromise. We hypothesise that diabetes leads to compromise of BBB tight junctions via stimulation of MMP activity. Materials and methods Diabetes was induced in the rat with streptozotocin. At 14 days after injection, BBB function was assessed by in situ brain perfusion. Tight junction proteins were assessed by immunoblot and immunofluorescence. Plasma MMP activity was quantified by fluorometric gelatinase assay and gel zymography.

Results In streptozotocin-treated animals, permeability to $\left[{ }^{14} \mathrm{C}\right]$ sucrose increased concurrently with decreased production of BBB tight junction proteins occludin (also known as OCLN) and zona occludens 1 (ZO-1, also known as tight junction protein 1 or TJP1). Insulin treatment, begun on day 7, normalised blood glucose levels and
\end{abstract}

Electronic supplementary material Supplementary material is available in the online version of this article at http://dx.doi.org/ $10.1007 / \mathrm{s} 00125-006-0485-\mathrm{z}$ and is accessible to authorised users.

B. T. Hawkins $\cdot$ T. F. Lundeen $\cdot$ K. M. Norwood

R. D. Egleton $(\bowtie)$

Department of Medical Pharmacology,

The University of Arizona College of Medicine,

1501 N. Campbell Ave., P.O. Box 245050,

Tucson, AZ 85724-5050, USA

e-mail: rde@email.arizona.edu

H. L. Brooks

Department of Physiology,

The University of Arizona College of Medicine,

Tucson, AZ, USA attenuated BBB hyperpermeability to $\left[{ }^{14} \mathrm{C}\right]$ sucrose. Neither acute hyperglycaemia in naive animals nor acute normalisation of blood glucose in streptozotocin-treated animals altered BBB permeability to $\left[{ }^{14} \mathrm{C}\right]$ sucrose. Plasma MMP activity was increased in streptozotocin-treated animals.

Conclusions/interpretation These data indicate that diabetes increases BBB permeability via a loss of tight junction proteins, and that increased BBB permeability in diabetes does not result from hyperglycaemia alone. Increased plasma MMP activity is implicated in degradation of BBB tight junction proteins and increased BBB permeability in diabetes. Peripheral MMP activity may present a novel target for protection of the $\mathrm{BBB}$ and prevention of neurological complications in diabetes.

Keywords Blood-brain barrier - Diabetes .

In situ brain perfusion - Matrix metalloproteinase - Occludin . OCLN $\cdot$ Rat $\cdot$ Streptozotocin $\cdot$ TJP1 $\cdot$ ZO-1 Z Zymography

\author{
Abbreviations \\ BBB blood-brain barrier \\ HRP horseradish peroxidase \\ $K_{\text {in }} \quad$ unidirectional transfer coefficient \\ MMP matrix metalloproteinase \\ TBS Tris-buffered saline \\ $V_{\mathrm{D}} \quad$ volume of distribution \\ ZO-1 zona occludens 1 (also known as tight junction \\ protein 1 or TJP1)
}

\section{Introduction}

The cerebral microvascular endothelium is distinguished by the presence of the blood-brain barrier (BBB), consisting of: (1) epithelial-like tight junctions that restrict paracellular 
permeability; (2) highly regulated membrane transporters that mediate the passage of molecules through the endothelium; and (3) metabolic enzymes. In concert with astrocytes, pericytes, neurons and the extracellular matrix, the BBB forms a neurovascular unit that protects the brain from circulating neurotoxic substances while maintaining nutrients and ions in the brain at levels necessary for neuronal function. Failure of the BBB is a critical event in the progression of several neurological diseases, indicating that the BBB may present a novel therapeutic target in these diseases if the mechanisms of BBB breakdown can be elucidated [1].

Microvascular complications of diabetes mellitus include diminished perfusion, abnormal endothelial proliferation, and increased permeability [2, 3]. Although diabetes is associated with increased risk of neurodegeneration [4] and dementia [5], the specific effects of diabetes on the BBB remain controversial. Diabetes has been associated with increased BBB permeability in some studies [6-9], whereas others have indicated that the $\mathrm{BBB}$ is maintained in diabetes [10-12].

Occludin (also known as OCLN), one of the extracellular components of the tight junction, restricts permeability to low molecular mass molecules and increases electrical resistance of barrier tissues; loss of occludin expression and/or translocation of occludin from the junction is associated with increased BBB permeability in diseases including inflammation, ischaemia and HIV encephalitis [1]. Occludin is also decreased following streptozotocin treatment in rats both in cerebral [13] and in retinal microvasculature [14]. Decreased occludin content in diabetic retinopathy may result from degradation by matrix metalloproteinases (MMPs) [15]. Expression and activity of the gelatinases MMP-2 and MMP-9 are increased by hyperglycaemia in vitro [3] and elevated in patients with type 1 [16] and type 2 [17] diabetes. Furthermore, MMP-2 and MMP-9 are known mediators of BBB opening [18, 19] and occludin proteolysis [20]. It is therefore possible that diabetes leads to compromise of BBB tight junction via stimulation of MMP activity. To address this hypothesis, we examined the effects of streptozotocin treatment on BBB permeability in the rat using in situ brain perfusion, and its effects on the expression of the BBB tight junction proteins occludin, claudin-5 and zona occludens 1 (ZO-1, also known as tight junction protein 1 or TJP1) using real-time PCR, immunoblot and immunofluorescence techniques. MMP activity in plasma was investigated by a fluorimetric gelatinase assay and by gel zymography.

\section{Materials and methods}

Animals and reagents All animal protocols in this study were approved by the University of Arizona Institutional
Animal Care and Use Committee and conform to National Institutes of Health guidelines stated in 'Principles of laboratory animal care' (NIH publication no. 85-23, revised 1985). Male Sprague-Dawley rats (3-4 months old, 270$330 \mathrm{~g}$ ) were purchased from Harlan (Indianapolis, IN, USA). Rats were fasted for $6 \mathrm{~h}$ prior to i.p. injection of either $60 \mathrm{mg} / \mathrm{kg}$ streptozotocin in sterile $0.9 \%$ saline or saline alone. Following injection, animals were returned to their cages, maintained under standard $12 \mathrm{~h}$ light-dark cycle, and given free access to food and water for the remainder of the study. Animals included in the insulin intervention studies were given insulin dissolved in sterile saline, $8 \mathrm{U} / \mathrm{kg}$ via intraperitoneal injection twice daily starting on day 7 , or a single dose $2 \mathrm{~h}$ prior to in situ brain perfusion in the acute insulin study. Hyperglycaemia was confirmed by urine test strips prior to commencement of insulin treatment, and animals were monitored following insulin injection for signs of severe hypoglycaemia (altered behaviour, ataxia, convulsions). Animals in the acute hyperglycaemia study were anaesthetised prior to injection of a $500-\mu \mathrm{l}$ bolus of either $50 \%$ glucose in saline or saline alone, followed by blood sampling and in situ brain perfusion within $10 \mathrm{~min}$. For all endpoints, animals were anaesthetised via intramuscular injection of $1 \mathrm{ml} / \mathrm{kg}$ of a cocktail containing ketamine $(78.3 \mathrm{mg} / \mathrm{ml})$, acepromazine $(0.6 \mathrm{mg} / \mathrm{ml})$ and xylazine $(3.1 \mathrm{mg} / \mathrm{ml})$ prior to in situ brain perfusion or decapitation. Terminal blood samples were collected from the tail veins of all animals prior to their being killed. Samples were tested for blood glucose, ketones and lipids with an analyser (CardioChek P.A; Polymer Technology Systems, Indianapolis, IN, USA) and/ or centrifuged for plasma and stored at $-20^{\circ} \mathrm{C}$. Animals were considered diabetic if blood glucose was $>16.7 \mathrm{mmol} / \mathrm{l}$; streptozotocin-treated animals with blood glucose $<16.7 \mathrm{mmol} / 1$ were excluded from the study.

Rabbit polyclonal anti-ZO-1 and anti-occludin, and mouse monoclonal anti-claudin-5 (also known as CLDN5) were purchased from Zymed (San Francisco, CA, USA). Horseradish peroxidase (HRP)-conjugated secondary antibodies were purchased from Amersham (Springfield, IL, USA). Alexafluor 488-conjugated secondary antibodies were obtained from Molecular Probes (Eugene, OR, USA). $\left[{ }^{14} \mathrm{C}\right]$ Sucrose (specific activity $37 \mathrm{MBq}$ ) was purchased from Amersham. All other reagents were purchased from Sigma (St. Louis, MO, USA), unless otherwise stated.

In situ brain perfusion Animals were anaesthetised as described above and given heparin $(10,000 \mathrm{U} / \mathrm{kg}$, i.p.) Following bilateral cannulation of the common carotid arteries, oxygenated Ringer solution $(117 \mathrm{mmol} / \mathrm{l} \mathrm{NaCl}$, $4.7 \mathrm{mmol} / 1 \mathrm{KCl}, 0.8 \mathrm{mmol} / 1 \mathrm{MgSO}_{4}, 24.8 \mathrm{mmol} / 1 \mathrm{NaHCO}_{3}$, $1.2 \mathrm{mmol} / 1 \mathrm{KH}_{2} \mathrm{PO}_{4}, 2.5 \mathrm{mmol} / \mathrm{l} \mathrm{CaCl} 2,10 \mathrm{mmol} / \mathrm{l} \mathrm{D}$-glucose, 
$39 \mathrm{~g} / 1$ 70-kDa dextran, $1 \mathrm{~g} / \mathrm{l}$ bovine serum albumin and $0.055 \mathrm{~g} / 1$ Evans Blue, heated to $37^{\circ} \mathrm{C}$ ) was infused via a peristaltic pump. Once desired flow-rate and perfusion pressures (approximately $3 \mathrm{ml} / \mathrm{min}$ and $100 \mathrm{mmHg}$ ) were achieved, $\left[{ }^{14} \mathrm{C}\right]$ sucrose $(370 \mathrm{kBq}$ per $20 \mathrm{ml}$ Ringer) was infused $(0.5 \mathrm{ml} / \mathrm{min}$ per hemisphere) using a syringe pump for $5,10,15$, or $20 \mathrm{~min}$. At the end of the perfusion, samples of the perfusate were collected and the brain was removed. Cerebral hemispheres were stripped of meninges and choroid plexuses and homogenised by hand. Tissue and $100-\mu l$ samples of perfusate were thoroughly mixed with tissue solubiliser (TS-2; Research Products, Mount Pleasant, IL, USA) and incubated for 2 days. Samples were prepared for scintillation counting by the addition of $100 \mu \mathrm{l} 30 \%$ acetic acid and $2.5 \mathrm{ml}$ liquid scintillation cocktail (OptiPhase SuperMix; Perkin Elmer, Boston, MA, USA) and counted on a liquid scintillation counter (Microbeta Trilux; Perkin Elmer). Results are reported as the ratio of radioactivity in the brain to that in the perfusate $\left(R_{\mathrm{br}}, \mu \mathrm{l} / \mathrm{g}\right)$ :

$R_{\mathrm{br}}=\left(C_{\text {brain }} / C_{\text {perfusate }}\right)$

where $C_{\text {brain }}$ is the radioactivity measured in brain $(\mathrm{dpm} / \mathrm{g})$ and $C_{\text {perfusate }}$ that in the perfusate $(\mathrm{dpm} / \mu \mathrm{l})$. In multi-timepoint uptake studies, unidirectional transfer coefficients $\left(K_{\text {in }}\right)$ were estimated for each group from the slope of a leastsquares regression of $R_{\mathrm{br}}$ vs perfusion time [21]:

$R_{\mathrm{br}}(t)=V_{\mathrm{D}}+K_{\text {in }} T$

where $V_{\mathrm{D}}$ is the initial volume of distribution of $\left[{ }^{14} \mathrm{C}\right]$ sucrose and $T$ is the perfusion time (min).

Cerebral microvessel isolation Cerebral microvessels were isolated from freshly removed brains as previously described [22]. For protein extraction, isolated microvessels were placed in $6 \mathrm{~mol} / \mathrm{l}$ urea buffer $(6 \mathrm{~mol} / 1 \mathrm{urea}, 10 \mathrm{mmol} / 1 \mathrm{Tris}$ base, $1 \mathrm{mmol} / 1$ dithiothreitol, $5 \mathrm{mmol} / 1 \mathrm{MgCl}_{2}, 5 \mathrm{mmol} / \mathrm{l}$ EGTA, $150 \mathrm{mmol} / 1 \mathrm{NaCl}, \mathrm{pH}=8.0$, one tablet per $10 \mathrm{ml}$ EDTA-free protease inhibitor [Complete Mini EDTA-free Protease Inhibitor; Roche, Mannheim, Germany]) and incubated at $4^{\circ} \mathrm{C}$ overnight. Protein was quantified using the bicinchoninic acid method (Pierce, Indianapolis, IL, USA) with BSA as a standard, and samples were frozen at $-20^{\circ} \mathrm{C}$ for use within a week or at $-80^{\circ} \mathrm{C}$ for use at a later time. For mRNA extraction, all isolation buffers were made in water treated with diethyl pyrocarbonate, microvessels were suspended in TRIZOL (Invitrogen, Carlsbad, CA, USA), and mRNA was isolated per manufacturer's protocol and stored at $-80^{\circ} \mathrm{C}$ until use.

Western blot Protein samples $(20 \mu \mathrm{g})$ were loaded on to 4 to $20 \%$ Tris- $\mathrm{HCl}$ gels (Ready Gels; Biorad, Hercules, CA, USA) and separated with $200 \mathrm{~V}$ for $30 \mathrm{~min}$, followed by electrophoretic transfer to polyvinylidene difluoride mem- branes $(240 \mathrm{~mA}, 45 \mathrm{~min})$. Membranes were blocked overnight at $4{ }^{\circ} \mathrm{C}$ in Tris-buffered saline (TBS) with $0.5 \%$ Tween-20 and 5\% non-fat dry milk, then incubated in primary antibody overnight at $4^{\circ} \mathrm{C}$. Membranes were washed several times with TBS-Tween-20-milk followed by TBS-Tween-20 without milk prior to incubation with HRP-conjugated secondary antibody for $45 \mathrm{~min}$ at room temperature, after which membranes were washed again, developed using enzyme chemiluminescence (ECLplus, Amersham), and visualised on X-ray film. Semiquantitation of scanned films was performed using Scion Image (Scion, Frederick, MD, USA), with gel staining (Gelcode; Pierce, Rockford, IL, USA) used to confirm consistency of protein loading. Results are reported as percent expression of control. Primary and secondary antibodies were diluted $1: 2,000$ in $0.5 \%$ BSA in PBS.

Real-time PCR cDNA was synthesised using a kit (Superscript III First-Strand Synthesis SuperMix; Invitrogen) per manufacturer's protocol and stored at $-20^{\circ} \mathrm{C}$ until use. Real-time PCR was performed with a sequence detection system (RotorGene RG3000; Corbett Life Sciences, Sydney, Australia) and a Quantitect Sybr Green PCR Kit (Qiagen, Valencia, CA, USA). Primers (Electronic supplementary material [ESM] Table 1) were designed using Primer3 software [23]. cDNA was diluted to $8 \mathrm{ng} / \mu \mathrm{l}$. The PCR reaction mixture contained $5 \mu \mathrm{l}$ of Sybr master mix, $0.4 \mu \mathrm{l}$ $25 \mathrm{mmol} / \mathrm{l} \mathrm{MgCl} 2,0.35 \mu \mathrm{l}$ RNAse-free water, $100 \mathrm{pmol}$ of forward and reverse primers, and $16 \mathrm{ng}$ cDNA in a volume of $10 \mu \mathrm{l}$. Reactions were performed in triplicate as previously described [24] at $95^{\circ} \mathrm{C}$ for $15 \mathrm{~min}$; then $95^{\circ} \mathrm{C}$ for $15 \mathrm{~s}, 58^{\circ} \mathrm{C}$ for $15 \mathrm{~s}$ and $20 \mathrm{~s}$ at $72^{\circ} \mathrm{C}$ for 40 cycles, followed by a melt cycle consisting of stepwise increase in temperature from 72 to $99^{\circ} \mathrm{C}$. Expression levels were calculated from cycle threshold numbers (threshold values) set within the exponential phase of the PCR normalised to endogenous cellular 18S RNA measured in parallel samples using 18S-specific primers.

Immunofluorescence microscopy Animals were anaesthetised as described above. Following transcardiac perfusion with $0.9 \%$ saline, brains were removed and snap-frozen in 2-methyl butane with dry ice. Brains were stored at $-80^{\circ} \mathrm{C}$ until cutting (minimum of $48 \mathrm{~h}$ ). All slides were prepared with matched saline and streptozotocin samples on the same slides. Coronal sections $(20 \mu \mathrm{m})$ from matched coordinates [25] were placed on to gelatine-coated slides and stored at $-80^{\circ} \mathrm{C}$ until use. Immunofluorescence staining for tight junction proteins was performed on the basis of previously described methods [26]. Slides were brought to room temperature, air dried, fixed in $100 \%$ ethanol for $10 \mathrm{~min}$, then washed in PBS followed by wash buffer (1\% BSA- $-2 \%$ Tween-20 in PBS). After blocking $90 \mathrm{~min}$ in 
normal goat serum (Vector Labs, Burlingame, CA, USA) diluted 1:50 in wash buffer, slides were incubated overnight with primary antibody to tight junction proteins diluted 1:500 in wash buffer; incubation was in humidified chambers at $4^{\circ} \mathrm{C}$. After rinsing with wash buffer, slides were incubated with appropriate fluorescent-tagged secondary antibody diluted 1:500 in wash buffer for $1 \mathrm{~h}$ at room temperature. Slides were rinsed with wash buffer and PBS and coverslips were mounted with Vectashield (Vector Labs). Microvessels were visualised on a laser scanning confocal microscope (Zeiss 510 Metaseries; Carl Zeiss Microimaging, Thornwood, NY, USA) with a $40 \times$ oil objective. Laser power, gain, pinhole, and all other image acquisition settings were maintained constant for image collection of matched saline and streptozotocin samples.

Fluorimetric gelatinase assay Tail blood was collected as described above. After centrifugation $(10,000 \mathrm{~g}, 5 \mathrm{~min})$, plasma was decanted and stored at $-20^{\circ} \mathrm{C}$ until use. Gelatinase activity was measured using a kit (EnzChek Gelatinase Assay; Molecular Probes). Plasma was diluted $1: 2$ in reaction buffer $(50 \mathrm{mmol} / \mathrm{l}$ Tris- $\mathrm{HCl}, 150 \mathrm{mmol} / \mathrm{l} \mathrm{NaCl}$, $5 \mathrm{mmol} / 1 \mathrm{CaCl}_{2}, 0.2 \mathrm{mmol} / \mathrm{l} \mathrm{NaN} \mathrm{N}_{3}, \mathrm{pH}=7.6$ ), mixed with DQ-gelatin $(1 \mathrm{mg} / \mathrm{ml}$, final concentration) and incubated at $37^{\circ} \mathrm{C}$. Fluorescence was measured (excitation: $485 / 20 \mathrm{~nm}$, emission: $530 / 25 \mathrm{~nm}$ ) with a fluorescence plate reader (FLx800; BioTek, Winooski, VT, USA) at various time points up to $180 \mathrm{~min}$.

Gel zymography Gel zymographic analysis was performed on plasma based on the methods of Asahi [27]. Plasma samples $(0.5 \mu \mathrm{l})$ were run with molecular mass markers and recombinant MMP-2 and MMP-9 standards (Sigma) under non-reducing conditions (without â-mercaptoethanol or dithiothreitol) on $10 \%$ Tris- $\mathrm{HCl}$ gels containing $0.5 \%$ gelatin (Criterion; Biorad). Enzymes were renatured in the gel with $2.5 \%$ Triton X-100 in deionised water for $1 \mathrm{~h}$ at room temperature. Gels were then equilibrated in a digestion buffer $\left(5 \mathrm{mmol} / 1 \mathrm{CaCl}_{2}, 50 \mathrm{mmol} / \mathrm{l}\right.$ Tris- $\mathrm{HCl}$, $\mathrm{pH}$ 7.4, $200 \mathrm{mmol} / \mathrm{l} \mathrm{NaCl}$, and $0.2 \% \mathrm{Brij} 35$ ) for $30 \mathrm{~min}$ at room temperature and then incubated for $24 \mathrm{~h}$ at $37^{\circ} \mathrm{C}$ in the same. Gels were stained with Brilliant Blue R (Biorad) for $1 \mathrm{~h}$, followed by destaining in multiple washes with $5 \%$ methanol-7.5\% acetic acid (until wash solution was clear, approximately $2 \mathrm{~h}$ ), then photographed and analysed with a Kodak Image station; clear bands were indicative of gelatinolytic activity.

Statistical analysis Student's $t$ test was used for comparison of two means, or in the case of more than two treatments, one-way ANOVA with a Tukey's post hoc test was used. Linear regression coefficients were compared using the pooled estimate of variation around the regression lines to calculate $T$ for comparison of $K_{\mathrm{in}}$ and $V_{\mathrm{D}}$ as previously described [28]. $p<0.05$ was considered statistically significant for all comparisons.

\section{Results}

Streptozotocin treatment was associated with a significant attenuation of weight gain; by day 14 post-injection, streptozotocin-treated animals displayed significant elevations in blood glucose, cholesterol and triacylglycerol (Table 1).

Permeability of the BBB to $\left[{ }^{14} \mathrm{C}\right]$ sucrose was measured by in situ brain perfusion (Fig. 1). $K_{\text {in }}$ for $\left[{ }^{14} \mathrm{C}\right]$ sucrose was $0.76 \pm$ $0.18 \mu \mathrm{g} \mathrm{g}^{-1} \mathrm{~min}^{-1}$ in the saline group, which is comparable to previously reported measurements [22]. In the streptozotocin-treated group, $K_{\text {in }}$ was significantly $(p=0.018)$ increased to $1.83 \pm 0.42 \mu \mathrm{g} \mathrm{g}^{-1} \mathrm{~min}^{-1}$, which coupled with the observation that $V_{\mathrm{D}}$ was not significantly different $(p=0.242)$ between the two groups (saline $=4.76 \pm 2.45 \mu \mathrm{l} / \mathrm{g}$; streptozotocin $=-2.16 \pm 5.92 \mu \mathrm{l} / \mathrm{g}$ ) indicates that streptozotocin treatment led to increased permeability of the BBB to $\left[{ }^{14} \mathrm{C}\right]$ sucrose.

To determine whether increased BBB permeability was the result of hyperglycaemia alone, we investigated the effect of long-term and acute alterations in blood glucose levels on sucrose distribution using single time point analysis [21]. Insulin treatment (8 U/kg twice daily) normalised blood glucose concentrations $(9.3 \pm 1.9 \mathrm{mmol} / \mathrm{l})$ and attenuated increased brain distribution of sucrose following streptozotocin treatment (Fig. 2a). However, acute normalisation of plasma glucose with a single dose of

Table 1 Blood chemistry and weight changes

\begin{tabular}{lll}
\hline & Saline & Streptozotocin \\
\hline Blood chemistry (mmol/l) & & \\
Glucose & $12.7 \pm 0.6$ & $30.8 \pm 1.3^{\mathrm{a}}$ \\
Ketones & $0.54 \pm 0.04$ & $0.57 \pm 0.09$ \\
Total cholesterol & $2.1 \pm 0.1$ & $2.7 \pm 0.2^{\mathrm{a}}$ \\
HDL & $0.9 \pm 0.1$ & $1.3 \pm 0.1^{\mathrm{a}}$ \\
LDL & $1.0 \pm 0.1$ & $0.7 \pm 0.2$ \\
Triacylglycerol & $0.3 \pm 0.0$ & $1.9 \pm 0.5^{\mathrm{a}}$ \\
Body weight (g) & & \\
Day 0 & $303 \pm 5$ & $301 \pm 4$ \\
Day 7 & $344 \pm 4$ & $306 \pm 6^{\mathrm{a}}$ \\
Day 14 & $359 \pm 3$ & $311 \pm 7^{\mathrm{a}}$ \\
\hline
\end{tabular}

Data are mean \pm SEM.

All measurements were taken in non-fasted animals. Streptozotocintreated animals with blood glucose $<16.7 \mathrm{mmol} / 1$ were excluded from the study.

${ }^{\mathrm{a}} p<0.01$ vs saline-treated 
insulin $(15.7 \pm 3.6$ vs $29.3 \pm 1.4 \mathrm{mmol} / 1$ in saline-treated controls, $p<0.01)$ had no statistically significant effect on sucrose distribution in streptozotocin-treated animals (Fig. 2b). In addition, acute hyperglycaemia $(24.1 \pm 3.6$ vs $12.7 \pm 1.8 \mathrm{mmol} / \mathrm{l}$ in saline-treated controls, $p<0.05$ ) induced by i.v. injection of glucose did not increase brain distribution of sucrose (Fig. 2c). Scatter plotting of all individual data points in these experiments showed that there is no significant correlation $(r=0.1340)$ between plasma glucose concentration and brain distribution of sucrose, following acute modulation of glucose or insulin (Fig. 2d).

In Western blot studies, all antibodies recognised bands at or near the expected molecular masses of each protein of interest (ZO-1, $220 \mathrm{kDa}$; occludin, $65 \mathrm{kDa}$; claudin-5, $22 \mathrm{kDa}$, Fig. 3b) in extracts from cerebral microvessels, as previously reported [22]. Expression of ZO-1 and occludin were significantly decreased to $58 \pm 8$ and $79 \pm 6 \%$, respectively, of saline-treated control levels in the streptozotocin group (Fig. 3a). Expression of claudin-5 was not significantly altered in streptozotocin-treated animals (Fig. 3a). Real-timePCR analysis indicated that mRNA levels for these tight junction proteins were unaltered in streptozotocin-treated animals (ESM Table 1).

Brain slices stained for ZO-1, occludin and claudin-5 all showed distinct, continuous bands of staining in brain microvessels indicative of concentration of these proteins at the junctions of the endothelial cells (Fig. 4), as previously described [26]. No changes in junctional localisation were observed for ZO-1, occludin or claudin-5 following streptozotocin treatment; however, the staining intensity for both ZO-1 and occludin appeared to be reduced, consistent with Western blot data (Fig. 3).

Gelatinolytic activity was measured in plasma using a fluorescence-based assay [29]. The rate at which DQgelatin was cleaved into fluorescent peptides was signifi-

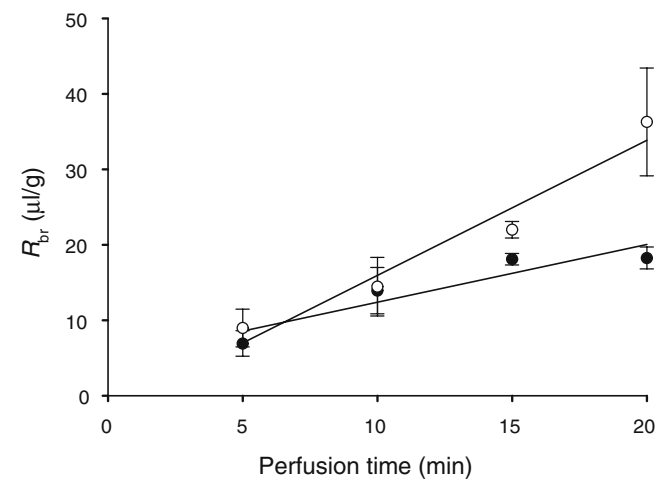

Fig. 1 In situ brain perfusion with $\left[{ }^{14} \mathrm{C}\right]$ sucrose. Values for the ratio of radioactivity in the brain to that in the perfusate $\left(R_{b r}\right)$ are mean \pm SEM, $n=3-5$ per time point. Closed markers, saline-treated; open markers, streptozotocin $(S T Z)$-treated. STZ significantly $(p<0.05)$ increased the rate of $\left[{ }^{14} \mathrm{C}\right]$ sucrose entry into the brain $\left(K_{\text {in }}\right)$ from $0.76 \pm 0.18$ to $1.83 \pm 0.42 \mu \mathrm{l} \mathrm{g}^{-1} \mathrm{~min}^{-1}$, whereas the initial volume of distribution $\left(V_{D}\right)$ for sucrose was not significantly different between the two groups ( saline $=4.76 \pm 2.45 \mu \mathrm{l} / \mathrm{g} ; \mathrm{STZ}=-2.16 \pm 5.92 \mu \mathrm{l} / \mathrm{g}$ ) cantly increased in plasma from streptozotocin-treated animals (Fig. 5a,b). Gel zymography of plasma samples confirmed this finding, with a significant $(p<0.001)$ increase in gelatinolytic activity corresponding to the expected molecular mass of MMP-2 (72 kDa; Fig. 6).

\section{Discussion}

Streptozotocin injection is a well-established and robust model of type 1 diabetes that works by selectively killing the beta cells of the pancreas [30,31]. Table 1 shows that classic symptoms of untreated diabetes (wasting, hyperglycaemia and hyperlipidaemia) were induced by streptozotocin, along with pronounced polyuria and polydipsia. By investigating BBB changes at a relatively early time point (14 days post-injection), we were able to focus on the onset and early progression of the disease, which is analogous to the period in humans when diabetes is most likely to go undiagnosed and therefore untreated [32], a critical period with regard to microvascular complications [33].

Previous studies of BBB permeability in animal models of diabetes have yielded variable results, with some investigators reporting increased permeability [9] and others no change $[11,12]$. In this study, permeability of the BBB was measured by in situ brain perfusion, a highly sensitive method used to characterise movement of drugs into the brain [34] as well as changes in BBB permeability to tracer molecules with development [35], drugs [28], and disease [36]. The primary advantage of this approach is that the brain is isolated from the peripheral circulation, enabling complete control of tracer concentration and flow [34]. This is of particular importance in diabetes, as the elimination of many tracer molecules from the peripheral circulation is much more rapid than normal [37, 38]. Therefore, previous studies utilising peripheral infusion of tracers may have underestimated brain distributions of sucrose and mannitol in diabetic animals. In this study, streptozotocin treatment was associated with a 2.4-fold increase in the rate $\left(K_{\text {in }}\right)$ of $\left[{ }^{14} \mathrm{C}\right]$ sucrose entry into the brain without change in the initial volume of distribution $\left(V_{\mathrm{D}}\right)$ (Fig. 1), indicating that the BBB is indeed compromised in this model of diabetes, and also confirming recent findings in diabetic patients $[6,8]$.

In a separate set of experiments, we showed that treatment with insulin begun on day 7 following streptozotocin injection normalised blood chemistry and attenuated the change in sucrose distribution (Fig. 2a). Interestingly, acute systemic hyperglycaemia in naïve animals had no significant effect on brain distribution of sucrose (Fig. 2b), nor did acute normalisation of blood glucose and insulin in streptozotocin-treated animals (Fig. 2c). Therefore, al- 


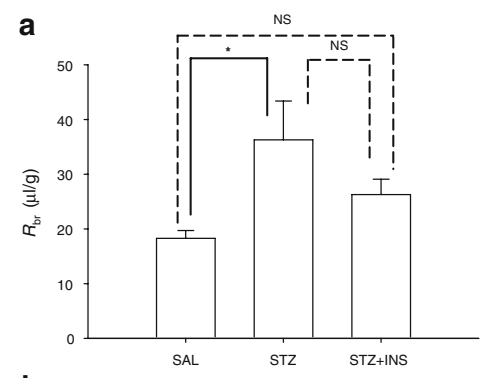

b

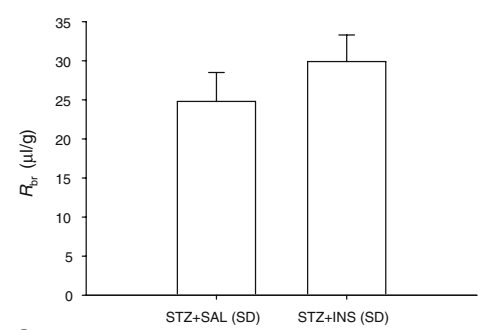

C

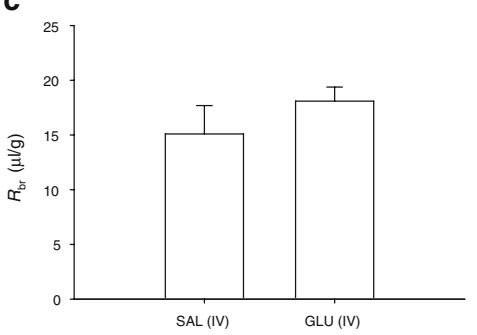

d

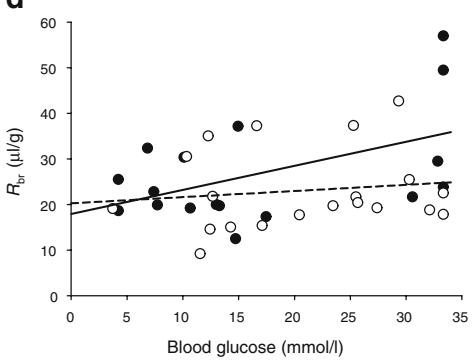

though BBB permeability changes do appear to occur downstream of hyperglycaemia in streptozotocin-induced diabetes, acute hyperglycaemia alone is not sufficient to induce the BBB changes observed in streptozotocin-treated rats. These data do not rule out the possibility that increased BBB permeability is the result of chronic hyperglycaemia and/or a chronic lack of insulin; indeed, the failure of acute normalisation of plasma glucose and insulin to restore $\mathrm{BBB}$ function in streptozotocin-treated animals (Fig. 2c) suggests that changes in BBB permeability in diabetes are timedependent. Further study is warranted to illuminate the time-dependent and specific effects of insulin and chronic hyperglycaemia on BBB function. In addition, exposure of confluent primary rat cerebral endothelial cells to plasma from streptozotocin-treated animals leads to increased sucrose permeability compared with cells treated with plasma from control animals [39]. However, permeability of cells treated with plasma from control animals with
4 Fig. 2 a-d Effects of blood glucose modulation on brain distribution of $\left[{ }^{14} \mathrm{C}\right]$ sucrose. Data in all panels are from single time point (20-min) in situ brain perfusions with $\left[{ }^{14} \mathrm{C}\right]$ sucrose. Data $(\mathbf{a}-\mathbf{c})$ are mean ratio of radioactivity in the brain to that in the perfusate $\left(R_{b r}\right) \pm \mathrm{SEM}, n=4-6$ per group. a Streptozotocin $(S T Z)$ significantly increased brain distribution of $\left[{ }^{14} \mathrm{C}\right]$ sucrose compared with saline $(S A L)$. Long-term insulin (INS) treatment normalised blood glucose levels and attenuated this increase, with brain distribution of $\left[{ }^{14} \mathrm{C}\right]$ sucrose not significantly different from SAL or STZ. SAL, 14 days post saline injection; STZ, 14 days post STZ injection; STZ+INS, 14 days post STZ injection with insulin $\left(8 \mathrm{U} / \mathrm{kg}\right.$, twice daily) begun on day $7 .{ }^{*} p<0.05, N S=$ not significantly different. Significance determined by one-way ANOVA with a Tukey's post hoc test. b Acute normalisation of blood glucose with a single dose $(8 \mathrm{U} / \mathrm{kg})$ of insulin immediately prior to perfusion did not normalise brain distribution of sucrose in STZ-treated animals. $S T Z+S A L(S D), 14$ days post STZ injection with a single dose of saline given prior to perfusion; $S T Z+I N S$ (SD), 14 days post STZ injection with a single dose of insulin ( $8 \mathrm{U} / \mathrm{kg}$ ) given prior to perfusion. c Acute hyperglycaemia induced by i.v. injection of a $50 \%$ glucose solution $(G L U)$ did not increase brain distribution of $\left[{ }^{14} \mathrm{C}\right]$ sucrose compared with saline-injected controls. SAL (IV), injection of a $500-\mu \mathrm{l}$ bolus of saline into the tail vein immediately prior to perfusion, GLU (IV), injection of a $500-\mu 1$ bolus of $50 \%$ glucose solution into the tail vein immediately prior to perfusion. d Scatter plot of all individual data points summarised in other panels. Linear regression of points from the long-term insulin study (a, solid circles, solid line) indicates a significant correlation between blood glucose and brain distribution of $\left[{ }^{14} \mathrm{C}\right]$ sucrose $(r=0.4997, p<0.05)$. Regression of points from acute modulation of glucose or insulin (b, c, open circles, dotted line) indicates no significant correlation between blood glucose concentration and brain distribution of $\left[{ }^{14} \mathrm{C}\right]$ sucrose $(r=$ $0.1340, p>0.50$ )

hyperglycaemic levels of glucose added is not significantly different from controls [39], suggesting the presence of a soluble factor in diabetic plasma that regulates BBB permeability.
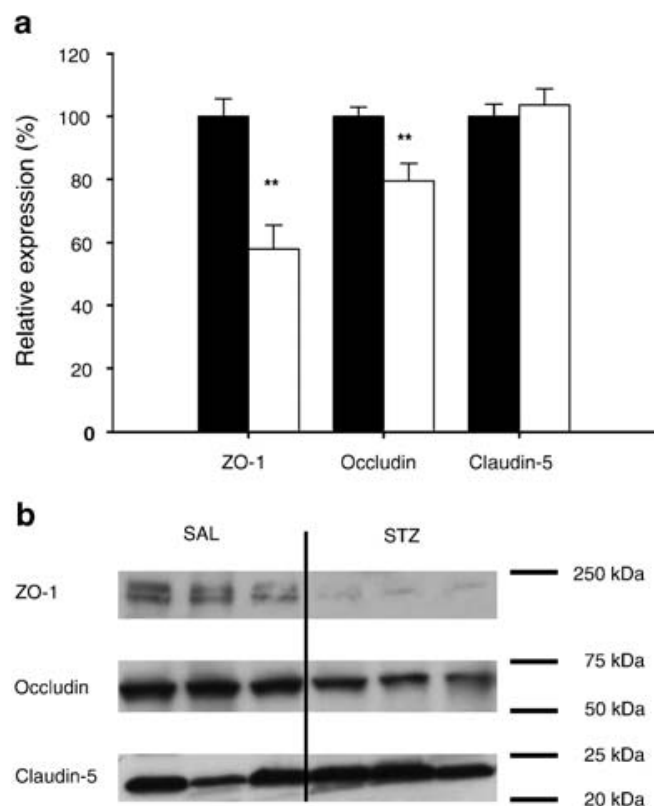

Fig. 3 Summary of Western blot data. a Data are the summary of two blots for each protein, $n=3$ unique samples per group per blot. Solid bars, saline-treated; open bars, streptozotocin-treated. Bars are mean percent expression of control \pm SEM $* * p<0.01$. b Representative blots 
Fig. 4 Microscopy of BBB tight junction proteins. Coronal sections $(20 \mu \mathrm{m})$ were stained for tight junction proteins. Saline $(S A L)$ and streptozotocin (STZ) samples from matched stereotaxic coordinates were placed on the same slides, and all microscope settings were kept constant for all images acquired within a slide. Panels show representative sections from SAL and STZ frontal cortex; all regions (parietal, temporal, occipital, hippocampal and subcortical) showed the same pattern of results. Images are $40 \times$ in oil immersion. Scale bar on inset $=20 \mu \mathrm{m}$
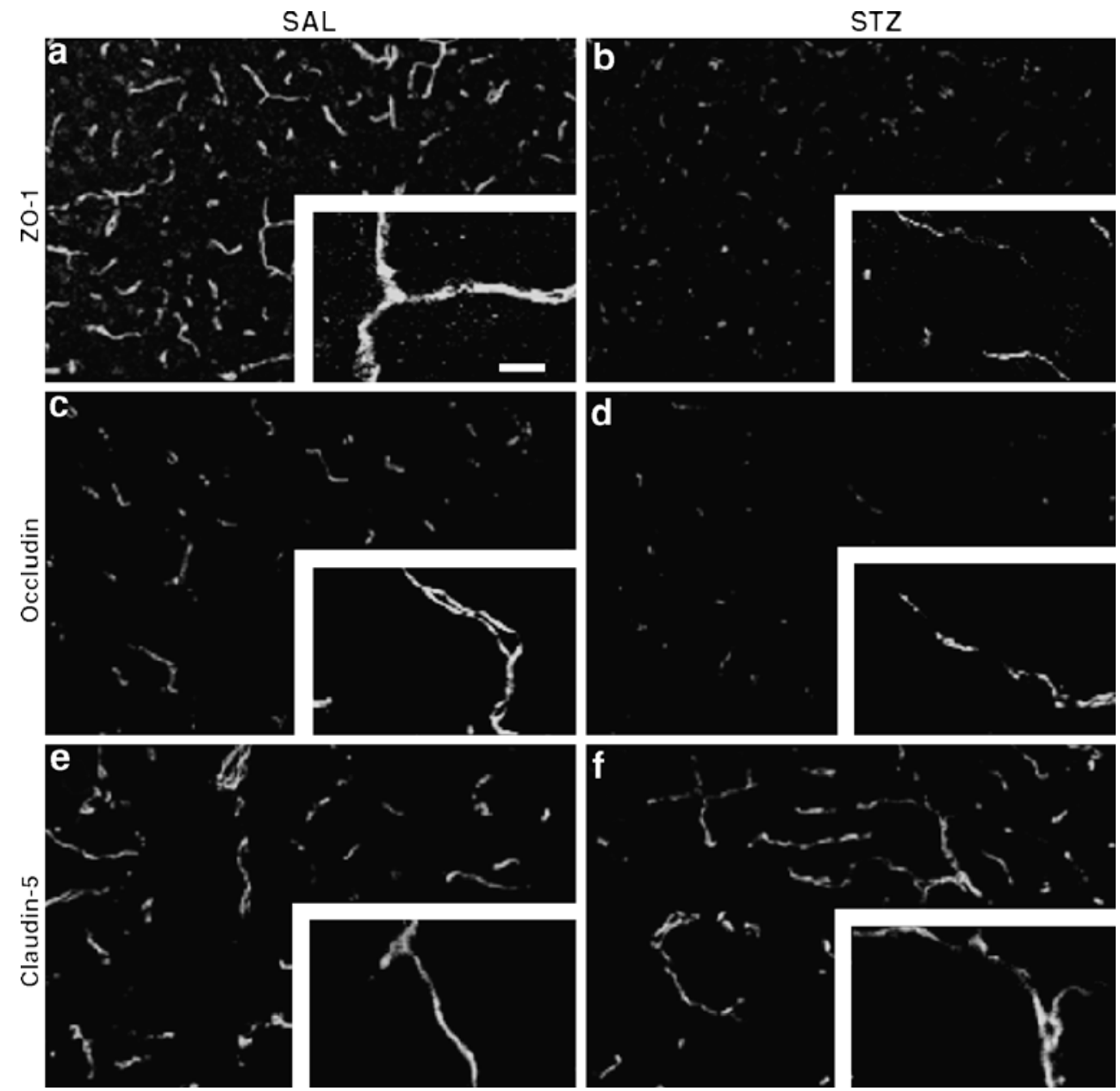

Increased distribution of a polar, water-soluble, nontransported molecule such as sucrose into the brain is indicative of increased paracellular diffusion at the BBB, a route normally blocked by tight junctions. Tight junctions are complexes of integral membrane proteins spanning intracellular clefts and cytoplasmic accessory proteins that link the transmembrane components to the actin cytoskeleton [40]. Changes in tight junction protein expression, posttranslational modification, subcellular localisation, and protein-protein interactions are associated with increased permeability [1]. A previous study indicated that streptozotocin-induced diabetes led to decreased protein expression of occludin, but not ZO-1, at the BBB [13]. In the present study, we observed decreased protein expression of both occludin and ZO-1 in cerebral microvessels of streptozotocin-treated rats, whereas claudin-5 expression remained constant (Figs. 3 and 4). This discrepancy might be explained by differences in tissue preparation. In the previous study, protein was taken from cortical homogenates, whereas we used an enriched preparation of cerebral microvessels. This is critical, as recently published work indicates that ZO-1 is expressed in neurons and glia as well as endothelial cells [41]. No changes were observed in mRNA levels for these tight junction proteins (ESM Table 1), suggesting that decreases in occludin and $\mathrm{ZO}-1$ content are not due to transcriptional downregulation. Since occludin and ZO-1 are likely substrates for the MMP-2 and/or MMP-9 [20, 42], we investigated the possibility that gelatinase activity was upregulated in our streptozotocin-treated animals.

Plasma gelatinase activity was first measured by a fluorimetric assay (Fig. 5) in which proteolysis of a dyequenched fluorescein-conjugated gelatin leads to liberation of fluorescent peptides. The rate of increase in fluorescent signal, therefore, was used to estimate the activity of MMP-2 and/or MMP-9 (Fig. 5). There was a statistically significant $(p=0.036) 46 \%$ increase in estimated gelatinase activity in plasma from streptozotocin-treated animals, which parallels recent findings in diabetic patient populations $[16,17,43]$. To determine the probable identity of the protease or proteases involved, gel zymographic analysis was performed on plasma samples (Fig. 6). Densitometric analysis indicated a small, but significant $(p<0.001)$ increase in gelatinolytic activity corresponding to $72 \mathrm{kDa}$, 
a

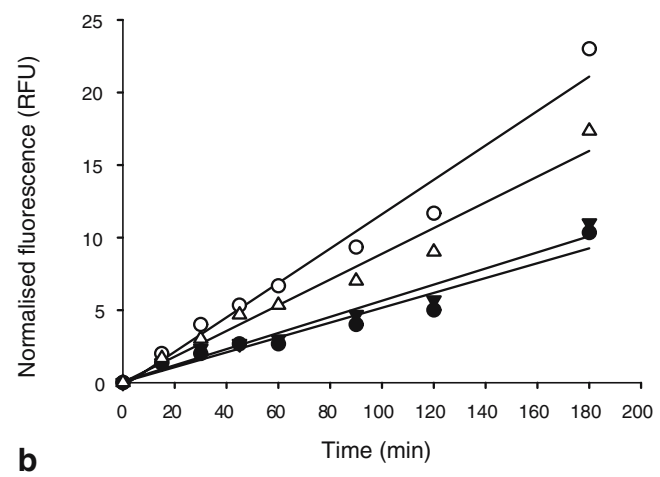

b

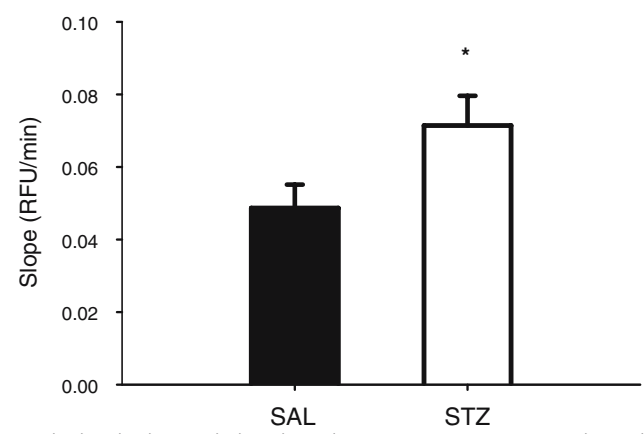

Fig. 5 Gelatinolytic activity in plasma. a Representative data from gelatinase activity assay in saline-treated ( $S A L$, solid symbols) and streptozotocin-treated (STZ, open symbols) plasma. Data are relative fluorescence units $(R F U)$ normalised to measurement at $t=0$. b Summary of all gelatinase activity measurements in plasma. Data are mean of plot slopes as shown in (a) \pm SEM; $n=15$ and 13 for SAL and STZ groups, respectively. ${ }^{*} p<0.05$

the expected molecular mass of MMP-2 (Fig. 6b). Interestingly, the MMP-9 standard used also showed proteolytic activity corresponding to this molecular mass as well as the expected molecular mass of $95 \mathrm{kDa}$ for this enzyme; however, no activity corresponding to the expected molecular mass of MMP-9 was observed in our samples (Fig. 6a).

Visualisation of gelatinolytic activity in the brain by in situ zymography did not show any obvious changes associated with streptozotocin treatment (data not shown). This indicates that either changes in brain MMP activity with diabetes are too subtle or diffuse to be visualised by this technique, or that any increase in MMP activity is in fact limited to the peripheral circulation in this model. Increased MMP-9 levels in the peripheral circulation, but not in the brain itself, have also been associated with BBB leakage in a model of fulminant hepatic failure [44]. As the tight junction is located in the apical aspect of the interendothelial cleft [40], circulating MMPs would presumably have access to its extracellular components (e.g. occludin). A recent study found that occludin, but not claudin-5, was degraded by MMP-2 and MMP-9 in retinal endothelial cells, and that these MMPs were upregulated in streptozotocin-treated rats [15]. The present findings in diabetic brain are striking in their similarity, suggesting a

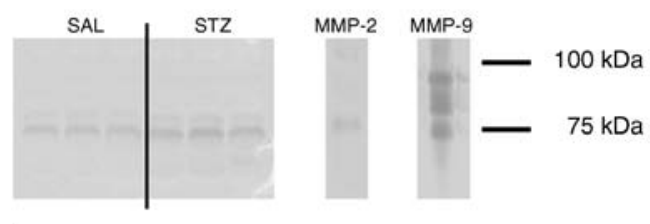

b

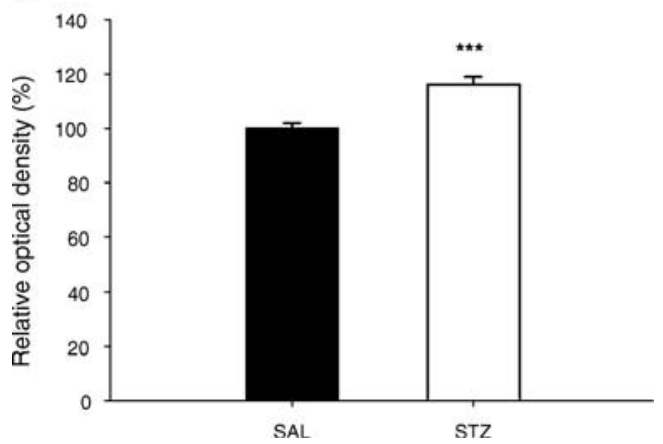

Fig. 6 Gel zymographic analysis of MMP activity in plasma. a A representative zymogram (inverse image shown for clarity) of plasma samples from saline $(S A L)$-treated and streptozotocin $(S T Z)$-treated animals with recombinant MMP-2 and MMP-9 included as standards. b Summary of data from three separate experiments. Data are mean relative optical density of the bands at $\sim 72 \mathrm{kDa}$ (MMP-2) \pm SEM; $n=9$ unique samples per group in total. $* * * p<0.001$

common pathophysiological mechanisms between the retinal and cerebral microvasculature.

In this study, we also observed a significant dyslipidaemia, with elevated cholesterol and triacylglycerol (Table 1). A recent study [9] indicated that statins have an ameliorating effect on cerebral endothelial changes induced by streptozotocin, indicating that hyperlipidaemia may also play a role. There is also evidence that statins can downregulate MMP-2 and MMP-9 activity independently of lipid modulation [45, 46], which, in light of the present finding of increased gelatinase activity in streptozotocin-treated rats, may also account for the protective effect of statins on the BBB. Another possibility that cannot be ruled out is that changes in BBB permeability occur secondary to peripheral inflammation in response to streptozotocin $[47,48]$. Further studies are warranted to clarify the possible interactions between MMP activity, hyperlipidaemia, inflammation, and BBB function.

In conclusion, we have demonstrated that streptozotocininduced diabetes leads to increased BBB permeability, that acute hyperglycaemia is not sufficient to induce this change, and that this change is associated with specific alterations in tight junction proteins. This indicates that microvascular complications similar to those affecting peripheral organs in diabetes may have a deleterious effect on the central nervous system, as well, and that glucose management alone may be insufficient for their prevention [6]. Compromise of BBB paracellular permeability along with alterations in BBB transport $[49,50]$ may present a 
link between diabetes and neurological complications associated with the disease. Finally, we have demonstrated that experimental diabetes is associated with increased gelatinolytic (MMP-2 and/or MMP-9) activity in the blood. The changes observed in this study are similar to those reported for both BBB permeability [6] and blood MMP activity $[16,17]$ in diabetic patients, suggesting that circulating MMPs are a potential target for prevention of neurovascular and neurological complications in diabetes.

Acknowledgements This work was supported by National Institute of Diabetes and Digestive and Kidney Diseases grant DK065003 to R. D. Egleton.

Duality of interest The authors have no duality of interest to disclose in connection with the results of this study.

\section{References}

1. Hawkins BT, Davis TP (2005) The blood-brain barrier/neurovascular unit in health and disease. Pharm Rev 57:173-185

2. Yamagishi S, Imaizumi T (2005) Diabetic vascular complications: pathophysiology, biochemical basis and potential therapeutic strategy. Curr Pharm Des 11:2279-2299

3. Kadoglou NP, Daskalopoulou SS, Perrea D, Liapis CD (2005) Matrix metalloproteinases and diabetic vascular complications. Angiology 56:173-189

4. Ristow M (2004) Neurodegenerative disorders associated with diabetes mellitus. J Mol Med 82:510-529

5. Biessels GJ, Staekenborg S, Brunner E, Brayne C, Scheltens P (2006) Risk of dementia in diabetes mellitus: a systematic review. Lancet Neurol 5:64-74

6. Starr JM, Wardlaw J, Ferguson K, MacLullich A, Deary IJ, Marshall I (2003) Increased blood-brain barrier permeability in type II diabetes demonstrated by gadolinium magnetic resonance imaging. J Neurol Neurosurg Psychiatry 74:70-76

7. Iwata A, Koike F, Arasaki K, Tamaki M (1999) Blood brain barrier destruction in hyperglycemic chorea in a patient with poorly controlled diabetes. J Neurol Sci 163:90-93

8. Hovsepyan MR, Haas MJ, Boyajyan AS et al (2004) Astrocytic and neuronal biochemical markers in the sera of subjects with diabetes mellitus. Neurosci Lett 369:224-227

9. Mooradian AD, Haas MJ, Batejko O, Hovsepyan M, Feman SS (2005) Statins ameliorate endothelial barrier permeability changes in the cerebral tissue of streptozotocin-induced diabetic rats. Diabetes 54:2977-2982

10. Dai J, Vrensen GF, Schlingemann RO (2002) Blood-brain barrier integrity is unaltered in human brain cortex with diabetes mellitus. Brain Res 954:311-316

11. Rechthand E, Smith QR, Latker CH, Rapoport SI (1987) Altered blood-nerve barrier permeability to small molecules in experimental diabetes mellitus. J Neuropathol Exp Neurol 46:302-314

12. Ennis SR, Betz AL (1986) Sucrose permeability of the bloodretinal and blood-brain barriers. Effects of diabetes, hypertonicity, and iodate. Invest Ophthalmol Vis Sci 27:1095-1102

13. Chehade JM, Haas MJ, Mooradian AD (2002) Diabetes-related changes in rat cerebral occludin and zonula occludens-1 (ZO-1) expression. Neurochem Res 27:249-252

14. Antonetti DA, Barber AJ, Khin S, Lieth E, Tarbell JM, Gardner TW (1998) Vascular permeability in experimental diabetes is associated with reduced endothelial occludin content: vascular endothelial growth factor decreases occludin in retinal endothelial cells. Penn State Retina Research Group. Diabetes 47:1953-1959

15. Giebel SJ, Menicucci G, McGuire PG, Das A (2005) Matrix metalloproteinases in early diabetic retinopathy and their role in alteration of the blood-retinal barrier. Lab Invest 85:597-607

16. Derosa G, Avanzini MA, Geroldi D et al (2005) Matrix metalloproteinase 2 may be a marker of microangiopathy in children and adolescents with type 1 diabetes mellitus. Diabetes Res Clin Pract 70:119-125

17. Signorelli SS, Malaponte G, Libra M et al (2005) Plasma levels and zymographic activities of matrix metalloproteinases 2 and 9 in type II diabetics with peripheral arterial disease. Vasc Med 10:1-6

18. Rosenberg GA, Estrada EY, Dencoff JE (1998) Matrix metalloproteinases and TIMPs are associated with blood-brain barrier opening after reperfusion in rat brain. Stroke 29:2189-2195

19. Mun-Bryce S, Rosenberg GA (1998) Gelatinase B modulates selective opening of the blood-brain barrier during inflammation. Am J Physiol 274:R1203-R1211

20. Wachtel M, Frei K, Ehler E, Fontana A, Winterhalter K, Gloor SM (1999) Occludin proteolysis and increased permeability in endothelial cells through tyrosine phosphatase inhibition. J Cell Sci 112( Pt 23):4347-4356

21. Williams SA, Abbruscato TJ, Hruby VJ, Davis TP (1996) Passage of a delta-opioid receptor selective enkephalin, [d-penicillamine2,5] enkephalin, across the blood-brain and the bloodcerebrospinal fluid barriers. J Neurochem 66:1289-1299

22. Hawkins BT, Abbruscato TJ, Egleton RD et al (2004) Nicotine increases in vivo blood-brain barrier permeability and alters cerebral microvascular tight junction protein distribution. Brain Res 1027:48-58

23. Rozen S, Skaletsky H (2000) Primer3 on the WWW for general users and for biologist programmers. Methods Mol Biol 132:365386

24. McReynolds MR, Taylor-Garcia KM, Greer KA, Hoying JB, Brooks HL (2005) Renal medullary gene expression in aquaporin1 null mice. Am J Physiol Renal Physiol 288:F315-F321

25. Paxinos G, Watson C (1998) The rat brain in stereotaxic coordinates. Academic, New York

26. Willis CL, Leach L, Clarke GJ, Nolan CC, Ray DE (2004) Reversible disruption of tight junction complexes in the rat bloodbrain barrier, following transitory focal astrocyte loss. Glia 48:1-13

27. Asahi M, Asahi K, Jung JC, del Zoppo GJ, Fini ME, Lo EH (2000) Role for matrix metalloproteinase 9 after focal cerebral ischemia: effects of gene knockout and enzyme inhibition with BB-94. J Cereb Blood Flow Metab 20:1681-1689

28. Hawkins BT, Egleton RD, Davis TP (2005) Modulation of cerebral microvascular permeability by endothelial nicotinic acetylcholine receptors. Am J Physiol, Heart Circ Physiol 289: H212-H219

29. Wang FQ, So J, Reierstad S, Fishman DA (2005) Matrilysin (MMP-7) promotes invasion of ovarian cancer cells by activation of progelatinase. Int J Cancer 114:19-31

30. Like AA, Rossini AA (1976) Streptozotocin-induced pancreatic insulitis: new model of diabetes mellitus. Science 193:415-417

31. Rakieten N, Rakieten ML, Nadkarni MR (1963) Studies on the diabetogenic action of streptozotocin (NSC-37917). Cancer Chemother Rep 29:91-98

32. Winer N, Sowers JR (2004) Epidemiology of diabetes. J Clin Pharmacol 44:397-405

33. Haffner SM, Stern MP, Hazuda HP, Mitchell BD, Patterson JK (1990) Cardiovascular risk factors in confirmed prediabetic individuals. Does the clock for coronary heart disease start ticking before the onset of clinical diabetes? JAMA 263:28932898

34. Bickel U (2005) How to measure drug transport across the bloodbrain barrier. NeuroRx 2:15-26 
35. Preston JE, al-Sarraf H, Segal MB (1995) Permeability of the developing blood-brain barrier to $14 \mathrm{C}$-mannitol using the rat in situ brain perfusion technique. Brain Res Dev Brain Res 87:69-76

36. Witt KA, Mark KS, Hom S, Davis TP (2003) Effects of hypoxiareoxygenation on rat blood-brain barrier permeability and tight junctional protein expression. Am J Physiol, Heart Circ Physiol 285:H2820-H2831

37. Maepea O, Karlsson C, Alm A (1984) Blood-ocular and bloodbrain barrier function in streptozocin-induced diabetes in rats. Arch Ophthalmol 102:1366-1369

38. Lorenzi M, Healy DP, Hawkins R, Printz JM, Printz MP (1986) Studies on the permeability of the blood-brain barrier in experimental diabetes. Diabetologia 29:58-62

39. Hawkins BT, Fleegal MA, McCaffery G, Egleton RD (2006) Contributions of hyperglycaemia and gelatinase activity to increased blood-brain barrier permeability in experimental diabetes. Society for Neuroscience, Annual Meeting (Abstract)

40. Bazzoni G, Dejana E (2004) Endothelial cell-to-cell junctions: molecular organization and role in vascular homeostasis. Physiol Rev 84:869-901

41. Penes MC, Li X, Nagy JI (2005) Expression of zonula occludens-1 (ZO-1) and the transcription factor ZO-1-associated nucleic acidbinding protein (ZONAB)-MsY3 in glial cells and colocalization at oligodendrocyte and astrocyte gap junctions in mouse brain. Eur J Neurosci 22:404-418

42. Harkness KA, Adamson P, Sussman JD, Davies-Jones GA, Greenwood J, Woodroofe MN (2000) Dexamethasone regulation of matrix metalloproteinase expression in CNS vascular endothelium. Brain 123:698-709

43. Jacqueminet S, Ben Abdesselam O, Chapman MJ et al (2006) Elevated circulating levels of matrix metalloproteinase-9 in type 1 diabetic patients with and without retinopathy. Clin Chim Acta 367:103-107

44. Nguyen JH, Yamamoto S, Steers J et al (2005) Matrix metalloproteinase-9 contributes to brain extravasation and edema in fulminant hepatic failure mice. J Hepatol 44:1105-1114

45. Nakaya R, Uzui H, Shimizu H et al (2005) Pravastatin suppresses the increase in matrix metalloproteinase-2 levels after acute myocardial infarction. Int J Cardiol 105:67-73

46. Nomura S, Yoshimura K, Akiyama N et al (2005) HMG-CoA reductase inhibitors reduce matrix metalloproteinase- 9 activity in human varicose veins. Eur Surg Res 37:370-378

47. Couture R, Harrisson M, Vianna RM, Cloutier F (2001) Kinin receptors in pain and inflammation. Eur J Pharmacol 429:161176

48. Huber JD, Hau VS, Borg L, Campos CR, Egleton RD, Davis TP (2002) Blood-brain barrier tight junctions are altered during a 72$\mathrm{h}$ exposure to lambda-carrageenan-induced inflammatory pain. Am J Physiol, Heart Circ Physiol 283:H1531-H1537

49. Banks WA, Jaspan JB, Kastin AJ (1997) Effect of diabetes mellitus on the permeability of the blood-brain barrier to insulin. Peptides 18:1577-1584

50. Mooradian AD (1987) Blood-brain barrier choline transport is reduced in diabetic rats. Diabetes 36:1094-1097 